\title{
EXPERIMENTAL INVESTIGATIONS AND VALIDATION OF A NEW MATERIAL MODEL DEVELOPED FOR MASONRY BRICKS
}

\author{
T. Linse ${ }^{1}$, N. Gebbeken ${ }^{1}$, T. Araújo ${ }^{1}$, R. M. Silva ${ }^{2}$ \\ ${ }^{1}$ Institute of Engineering Mechanics and Structural Mechanics, University of the Bundeswehr \\ Munich, Germany (tamara.araujo@unibw.de) \\ ${ }^{2}$ Department of Structural Engineering, Federal University of Minas Gerais, Brazil
}

\begin{abstract}
This paper presents static and dynamic material tests conducted for different types of bricks. Based on the results of these experimental investigations, a new material model for masonry bricks has been developed. This material model, which is suitable for a detailed micro-model approach, considers the dynamic increase of the material strength and the degradation of the material properties due to fracture and material damage. During this project a material model for mortar has been developed also, but it will not be shown here because of lack of space. The material models for the bricks and the mortar have been implemented in ANSYS AUTODYN and can be used to examine the complex material and structural behavior of masonry walls under dynamic loadings (e.g. explosions, earthquakes). In this paper, the material model developed for bricks and its validation for static tensile and compression tests will be presented.
\end{abstract}

Keywords: Masonry, bricks, experimental investigations, static and dynamic material model, detailed micro-model.

\section{INTRODUCTION}

Masonry is one of the most important construction materials used for buildings worldwide. A masonry wall is composed of masonry bricks and mortar; the bricks are joined together by the mortar. The bricks can be made of concrete, ceramic, stone, clay, glass, etc. Due to the extensive use of masonry around the world, it is necessary to better study the behavior of the material's components subjected to different actions. Nowadays a better protection and a better assessment of buildings against explosions and earthquakes are needed. These exceptional loadings show the necessity to develop models to allow the assessment of consequences of these specific dynamic actions. Masonry is a heterogeneous and anisotropic material due to the composition of the bricks and mortar. It shows nonlinear material as well as nonlinear structural behavior. Dynamic loadings cause large strains and large deformations resulting in an increase of material strength due to strain rate. In addition the degradation of the material's strength and stiffness after fracture must be considered. This requires appropriate material models that can realistically represent the nonlinear behavior of 
structures. In addition, masonry exists in very different types with respect to materials and construction techniques. A wide range of materials for masonry bricks and for mortar is used in practice. The different sizes of the bricks and the different possibilities to assemble the bricks must also be considered.

In this paper, the material model developed for bricks and its validation will be presented. The material data used for the material model for bricks was obtained from static and dynamic experiments conducted for five different bricks, Fig. 1. Their sizes and densities are presented in Table 1. The static material tests were mainly carried out at the University of the Bundeswehr in Munich, Germany. The dynamic material tests were carried out at the Joint Research Centre (JRC) of the European Commission, in Ispra, Italy.

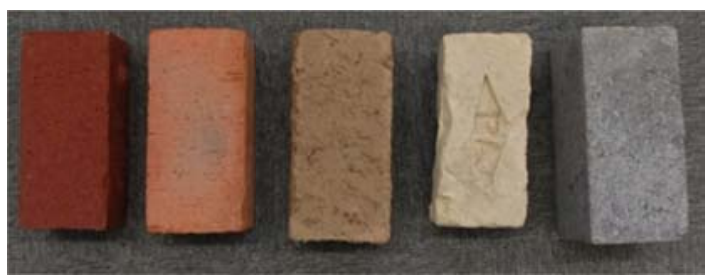

Figure 1. Examined bricks (left to right): clinker, ceramic, clay brick (Germany), clay brick (Afghanistan) and concrete

Table 1. Sizes and densities of the examined bricks

\begin{tabular}{ccc}
\hline Brick & Sizes $[\mathbf{m m}]$ & Density $\left[\mathbf{g} / \mathbf{d m}^{3}\right]$ \\
\hline Clinker & $237 \times 110 \times 71$ & 2143 \\
Ceramic & $239 \times 115 \times 72$ & 1807 \\
Clay Brick (Germany) & $247 \times 118 \times 66$ & 1139 \\
Clay Brick (Afghanistan) & $207 \times 100 \times 74$ & 1497 \\
Concrete & $241 \times 114 \times 114$ & 1899 \\
\hline
\end{tabular}

In the following, the experiments, the material model developed for the bricks and the validation of this model will be explained.

\section{MATERIAL PROPERTIES OF BRICKS}

As the model should be suitable for a wide range of brick types, a large amount of experimental data for bricks was collected. Although there is test data of experiments on masonry specimens existing, there is little data available for the components brick and mortar. Often, tests are performed on masonry specimens in order to determine the maximum bearing capacity. But the properties of the components are not reported or not tested at all. Nevertheless, there are some publications that deliver detailed information on bricks. Vermeltfoort and Pluijm [24] and Pluijm [15] carried out tests in order to determine the tensile strength of mortar joints, the compressive and tensile strength of different types of bricks and they determined Young's moduli for both materials. Sarangapani et al. [17] studied the bond between brick and mortar and published data for Indian mortar and bricks. Schubert [20, 21] and Brameshuber et al. [5] assembled further data, especially for typical German masonry materials. Masonry bricks can be made of, e.g., adobe, clay, clinker, concrete or calcium silicate. Consequently, the uniaxial compressive strength of masonry units, for 
example, can range from 3 to $100 \mathrm{MPa}$. In addition, there are more and more highly sophisticated masonry units with voids and internal thermal insulation in order to provide a better thermal insulation. Another challenge is the analysis of the results of the experiments, because testing methods show an important influence on the results of the tests.

\subsection{Static tensile experiments on bricks}

An important material parameter for bricks is the tensile strength, because bricks usually fail under tensile stresses and strains. Even if there is a uniform compressive stress in the plane of a masonry wall, besides lateral tension due to the Poisson effect, lateral tension is introduced in the bricks due to the mortar, which is weaker than the bricks. In order to study the tensile strength, three different experiments were performed: 1- uniaxial tensile tests on notched masonry bricks; 2- uniaxial tensile tests on un-notched bricks; and 3- Brazilian splitting tests. More details of the results of these tests will be published soon [11]. Fig. 2(a) shows a tensile test with a notched brick. This test delivers the tensile strength in a very small (homogeneous) region in the middle of the brick. The measured tensile strength is not influenced by small cracks that existing because of the drying and burning process of the bricks. Fig. 2(b) shows the test set up with the un-notched specimen. With this test the tensile strengths and the Young's moduli of the bricks were determined. The deformation of the bricks was recorded by inductive transducers, which provide an accurate measurement.
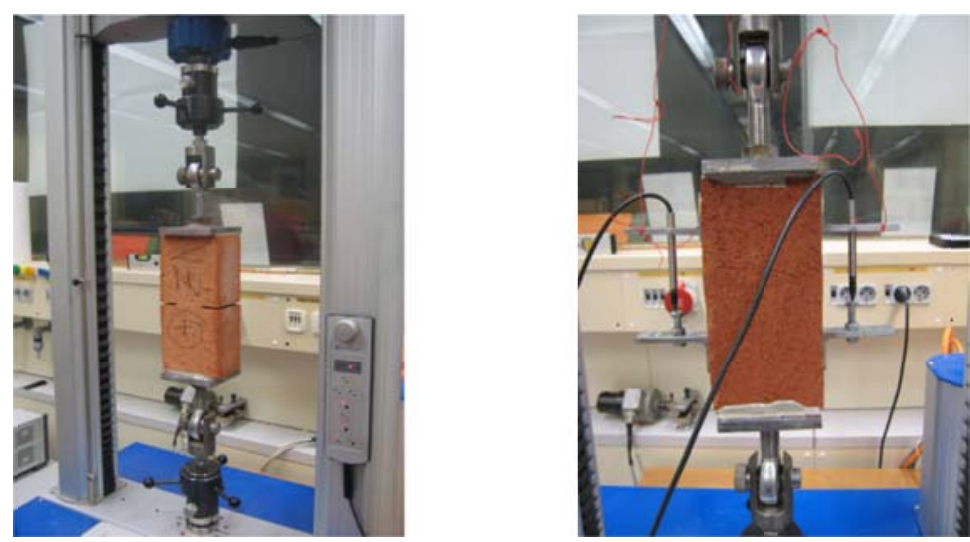

Figure 2. Tensile test with (a) notched bricks and (b) un-notched bricks, instrumented with inductive transducers attached to the bricks

The third test is the so called Brazilian splitting test, Fig. 3. The brick was pressed in the middle. Due to this load, transversal tensile stress in the center of the brick is generated. Fig. 3 shows a sketch of the test with a cylindrical specimen. The bricks were cut in specimens with diameter of $40 \mathrm{~mm}$ and length of $40 \mathrm{~mm}$.

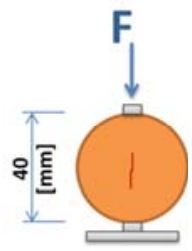

Figure 3. Brazilian splitting test 
The results of this third material test were used to compare the results of the SPHBtest to the static test, with the same specimen size. With this information the dynamic increase factor of the material under tensile stress was determined. More details about the necessity to include this factor will be explained in Chapter 3.

\subsection{Static compression experiments on bricks}

In order to determine the mechanical properties of the bricks under compression, four different tests were carried out: 1- uniaxial compression tests on one single brick, the largest side of the brick was loaded, 2- uniaxial compression tests of three bricks on top of each other in lying position; 3- uniaxial compression tests on one standing brick, 4- uniaxial compression tests with cylindrical geometries. Fig. 4 (a) shows test 2. The surfaces of the bricks were grinded in order to avoid gaps in the joints. Fig. 4 (b) shows the set-up of test 3 with one standing brick. With tests 2 and 3 Young's moduli of the bricks were determined. In order to measure the deformation of the bricks, inductive transducers were used.
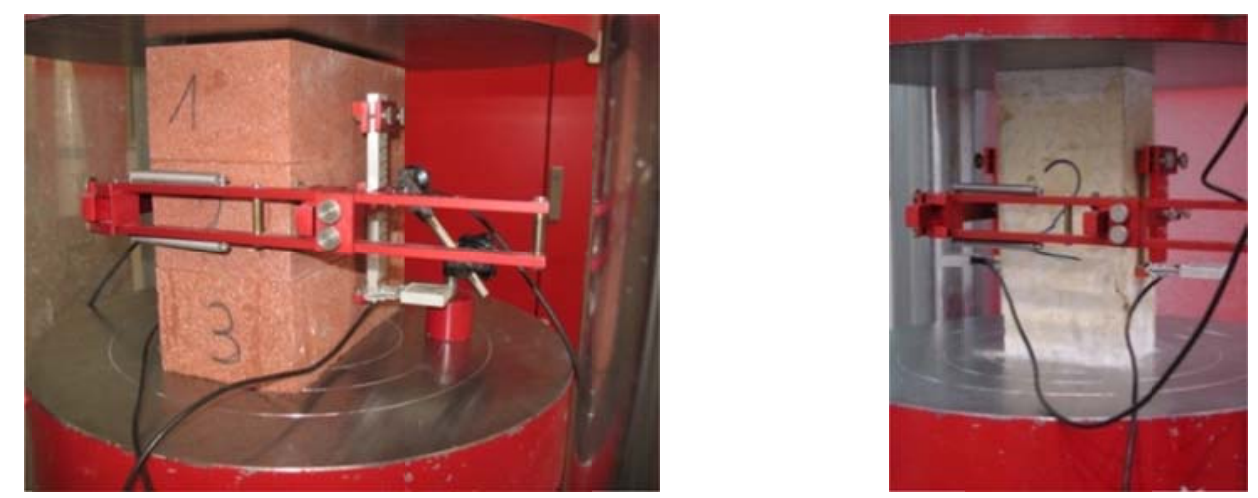

Figure 4. Compression tests conducted to determine: (a) the compression strengths of the bricks and (b) the Young's moduli of the bricks

The fourth material test was performed with cylindrical specimens, Fig. 5. The specimens had the same geometry like the specimens of the dynamic compression tests which will be described in the following paragraphs.
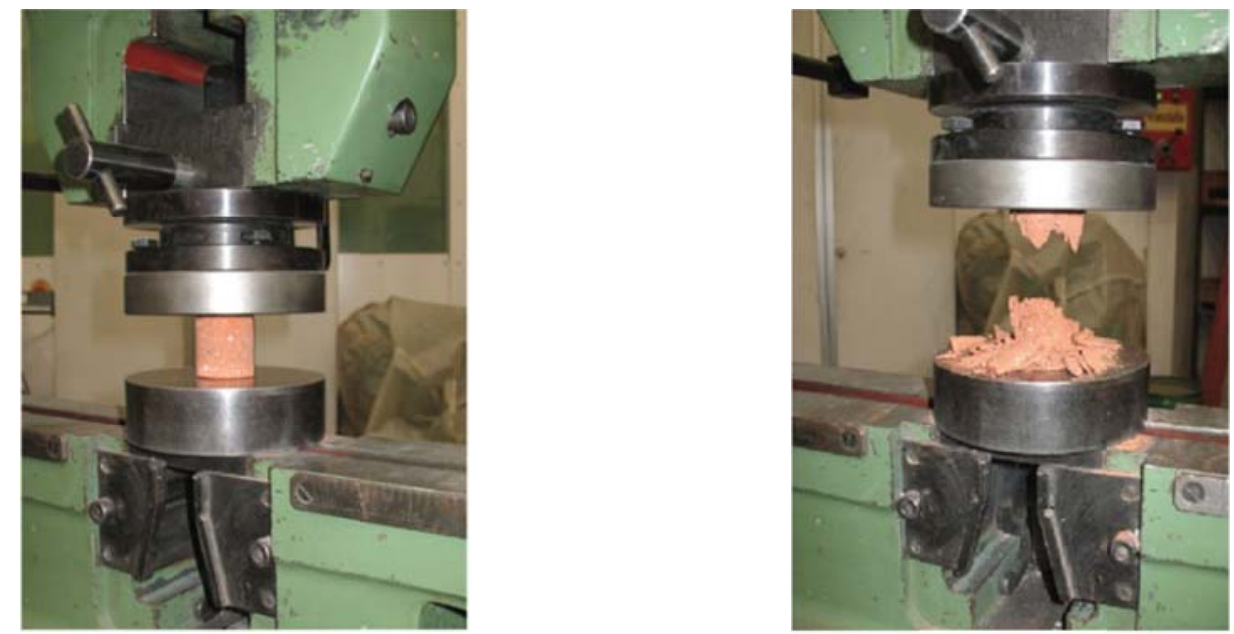

Figure 5. (a) compression test of cylindrical specimens before, and (b) after the test 


\subsection{Dynamic tensile and compression tests of bricks}

The behavior of materials under dynamic loads usually varies and should be considered in the material models in order to better represent the behavior of structures under dynamic loadings. Most materials show an increase of the strengths with an increase of the strain rate. In order to study the increase of the material strength, Split-Hopkinson-PressureBar tests were carried out at the JRC for three bricks: clinker, ceramic and the clay brick from Afghanistan. To determine the increase of the tensile strength Brazilian splitting tests were conducted. Fig. 6 shows the propagation of the crack during the dynamic Brazilian splitting test. Fig. 7 presents the set-up of the dynamic Split-Hopkinson-Pressure-Bar test.

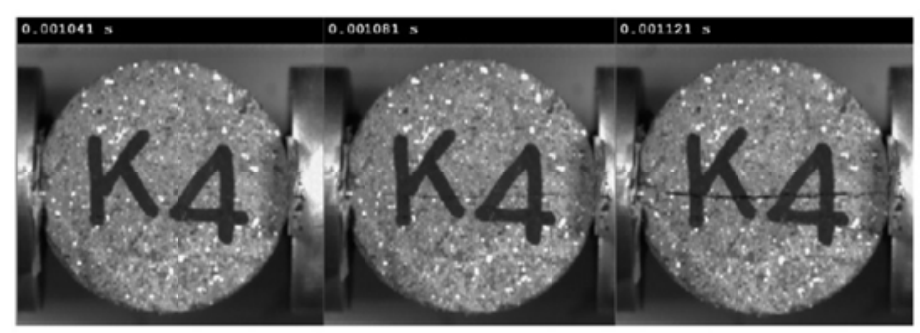

Figure 6. Crack propagation during tensile test (Brazilian test)

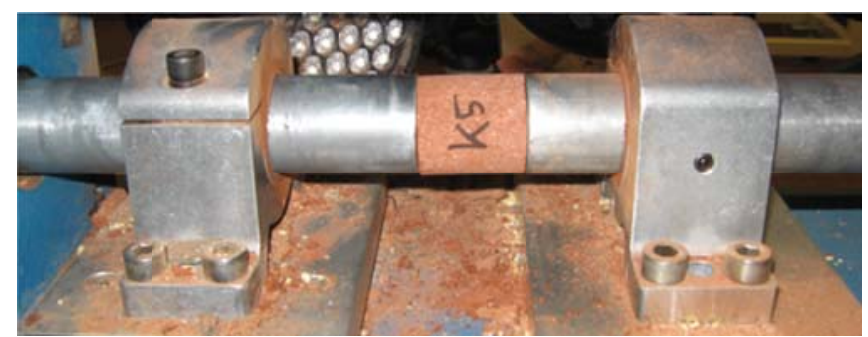

Figure 7. Compression test in Split-Hopkinson-Pressure-Bar

With these tests, it could be determined that the strain rate dependency for bricks is much smaller than for concrete at the same strain rate. The comparisons are presented in Fig. 10 and Fig. 11. It is also possible to observe in these figures that the dynamic increase factor of the ceramic brick is almost 1 for both cases. This means, that under dynamic loads the strength does not change. More experiments are planned in order to verify these results.

\subsection{Material tests - Conclusion}

The static and dynamic experimental investigations show that the tensile and the compressive strengths depend on the geometry of the specimen. This problem was already recognized and discussed by Schickert [18] for compression tests on concrete, for example. The correct strength values for the bricks are still not obvious, although there are correction factors existing, that should compensate the influence of the geometry. For the tensile tests the geometry of the specimen plays an important role, too. If a large specimen, like in Fig. $2 b$, is used, the tensile strength of the whole brick is determined. So, the cracks due to the drying and shrinking process are included. If the tensile strength is determined with the notched specimen, Fig. 2a, the tensile strengths are determined for a very small part of the specimen.

Another interesting result of the tests is that the Young's modulus is different for 
tensile and compressive loadings. The reason for this is probably small cracks due to the drying and burning process of the bricks. If a compressive load is applied, the cracks are closed by the external load, for tension the external load opens the cracks. This difference of the stiffness should be taken into account in the material model in order to be able to model the failure due to the lateral deformation of the joints as good as possible. The material properties that are used for the numerical simulations are plotted in table 2.

In this paper only some aspects of the material tests could be briefly described. More results and a detailed analysis of the tests will be published in the near future [11].

\section{NUMERICAL MODELING STRATEGIES}

There are several strategies to model masonry walls, Fig. 8. These strategies can be classified into two main groups: macro-models and micro-models. Micro-models are usually distinguished between simplified and detailed micro-models. In the following, a brief description of each method will be presented.

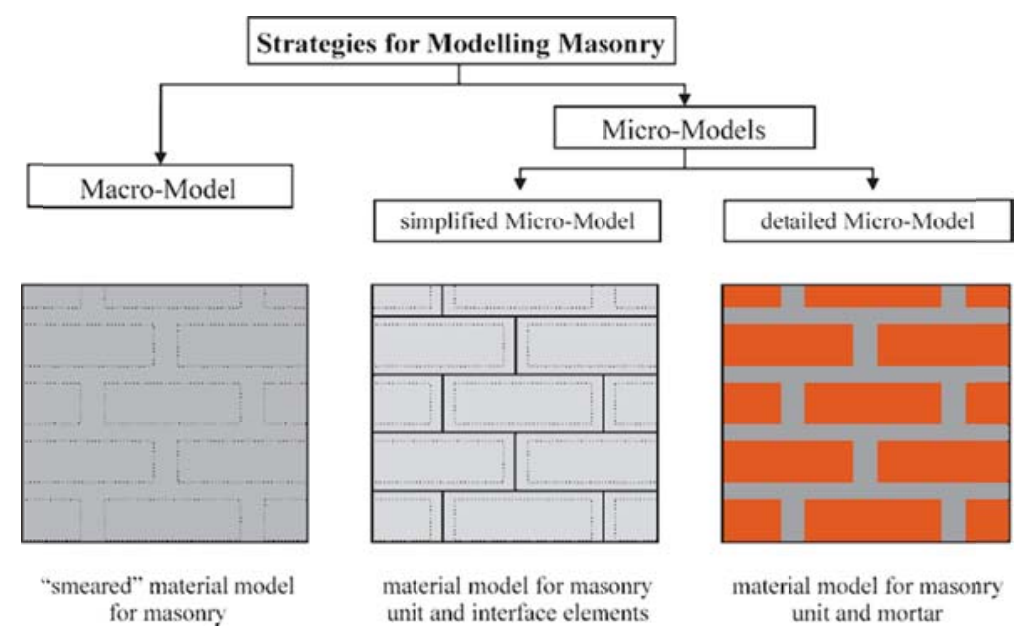

Figure 8. Strategies for numerically modeling masonry

\section{Macro-Models:}

The inhomogeneous composite material masonry, composed of the two materials, mortar and bricks, are numerically replaced by one homogeneous matterial. This means, that the properties of the brick, the mortar and the transition zone between mortar and brick are homogenized and described by one material model. As a consequence, some information about the individual constituents can be lost. Macro-models are often used to model entire masonry structures.

\section{Simplified Micro-Model:}

The simplified micro-model distinguishes between the masonry units and the mortar joints. The mortar joints are numerically described by interface elements, which describe the material properties of the mortar. At the same time, they describe the properties of the transition zone and the bond between brick and mortar. The interface elements usually do not have a thickness. So the sizes of the masonry units have to be adapted. In order to model the properties of the mortar joints and the bond between mortar and brick nonlinear spring elements can be used as well as material models. 


\section{Detailed Micro-Model:}

Using the detailed micro-model approach the bricks and the mortar joints have their real sizes. Bricks and mortar are modeled with continuum elements. In addition, interface elements can be used to describe the bond between the brick and the joint. Using the detailed micro-model, the Young's modulus, the lateral deformation and the inelastic material properties of the mortar and the bricks can be modeled separately. This is important in order to assess the failure due to lateral tension in the bricks. So, the interaction between the mortar and the bricks and the different failure modes can be realistically determined.

\subsection{Our Approach}

For this project a modeling approach is needed that is able to simulate masonry walls made of any types of masonry units and any arrangement of the units under dynamic loadings. For this vast range of application, including loadings in and perpendicular to the wall, an appropriate modeling strategy is needed. As loadings perpendicular to the plane of the wall cause normal tensile and compression stresses in the wall, it is important to numerically model the interaction between the mortar and the bricks, because normal compression creates tensile failure in the bricks due to lateral deformation of the joints. Therefore, the detailed micro-model has been chosen for the own modeling approach.

As mentioned before, in this paper, just the material model developed for bricks and its validation is presented. In Gebbeken et al. [7] the material model developed for mortar is published in detail.

\subsection{Material model for bricks}

The material model developed for bricks is designed to perform three dimensional simulations. The main challenge has been the development of a formulation that can be easily adapted to different brick types. In the following paragraphs the mechanical descriptions implemented in the material model for the bricks are presented.

\section{Strength model}

In order to better understand the idea of the construction of the strength model, the position of different stress states on the fracture surface and the different meridians are presented in Fig. 9. 


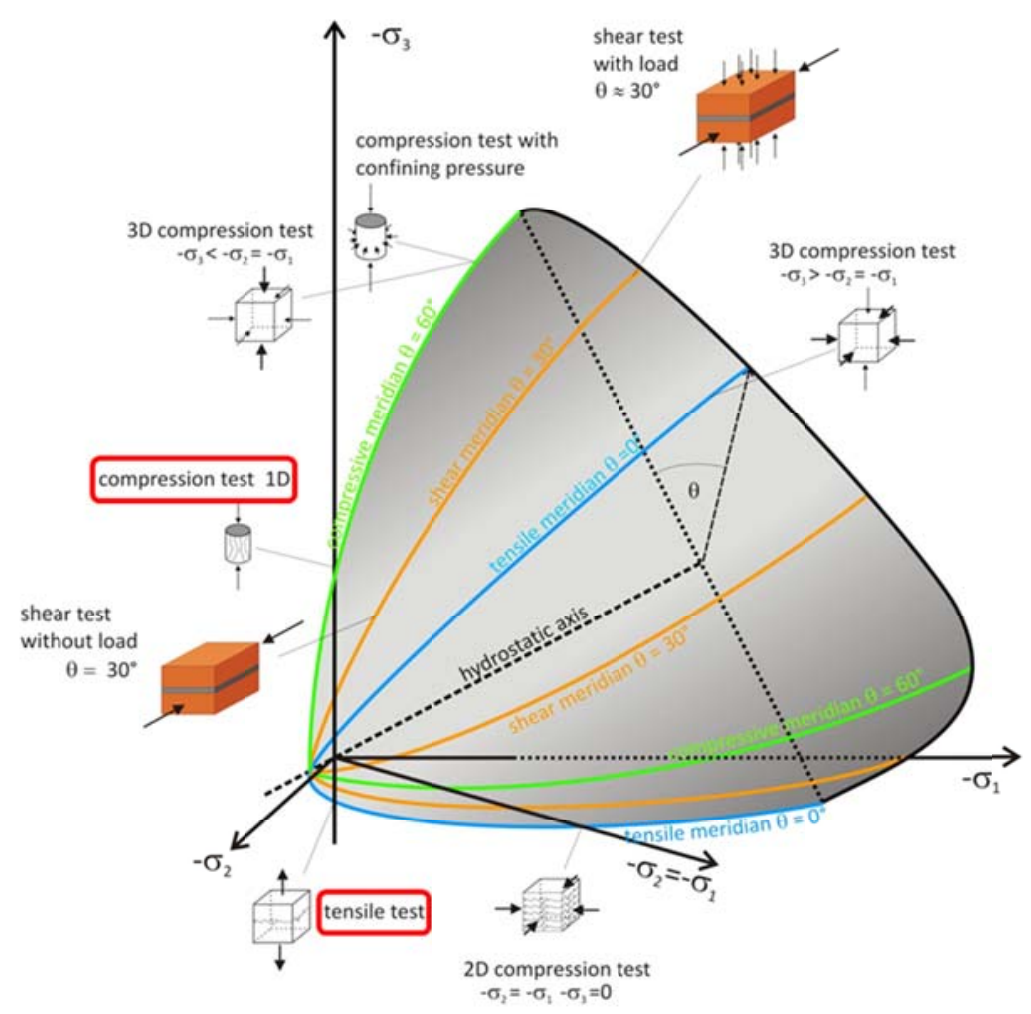

Figure 9. Representation of the position of material tests on the stress surface

For the purpose of the development of the strength model, approaches that could be found in the literature were analyzed. The material model for ceramics published by Johnson and Holmquist [10] and the model by Hao and Tarasov [8] were investigated. Both models are based on assumptions that are not quite valid for our purposes. Consequently, a new fracture surface has been developed. Fracture surfaces published by Willam \& Warnke [25], Ottosen or Thomée [23] could be starting points for the own development. Finally, the Ottosen-Speck model was chosen. This is the Ottosen model with an extension by Speck [22]. For this model, a wide range of applicability for normal and ultra-high performance concretes is proofed. The fracture surface is defined by

$$
\mathrm{f}_{\text {Ottosen-Speck }}\left(\mathrm{I}_{1}, \mathrm{~J}_{2}, \theta\right)=\mathrm{A} \frac{\mathrm{J}_{2}}{\left|\mathrm{f}_{1 \mathrm{c}}\right|^{2}}+\lambda \frac{\sqrt{\mathrm{J}_{2}}}{\left|\mathrm{f}_{1 \mathrm{c}}\right|}+\frac{\mathrm{BI}_{1}}{\left|\mathrm{f}_{1 \mathrm{c}}\right|}-1=0
$$

with

$$
\lambda=\mathrm{k}_{1} \cos \left(\frac{\pi}{3}-\frac{1}{3} \arccos \left(-\mathrm{k}_{2} \cos (3 \theta)\right)\right) \cos (3 \theta)<0
$$

In order to fit this strength model for bricks, test data for at least four different stress states are necessary: 1-D compression, 1-D tension, a 2-D test on the tensile meridian, and a 3-D test on the compressive meridian. The necessary material parameters are the uniaxial compression strength $f_{c}$, the two dimensional compression strength $f_{c c}$, the uniaxial tensile strength $\mathrm{f}_{t}$, and a three dimensional compression test on the compressive meridian defined by $\sigma_{0}$ and $\tau_{0}$. Having this test data, the calibration can be done with the following equations:

$$
H=-\frac{\sqrt{2} \cdot x+y}{\frac{y}{\sqrt{2}}-\frac{1}{3}}
$$




$$
\begin{gathered}
\mathrm{k}=\frac{\mathrm{f}_{\mathrm{ct}}}{\left|\mathrm{f}_{\mathrm{c}}\right|} \quad \mathrm{f}_{2 \mathrm{c}}=\frac{\mathrm{f}_{\mathrm{cc}}}{\left|\mathrm{f}_{\mathrm{c}}\right|} \\
\mathrm{x}=\frac{\sigma_{0}}{\left|\mathrm{f}_{\mathrm{c}}\right|} \quad \mathrm{y}=\frac{\mathrm{c}_{0}}{\left|\mathrm{f}_{\mathrm{c}}\right|} \\
\mathrm{B}=\frac{\sqrt{2}-\frac{3 \cdot \mathrm{y}}{\mathrm{k} \cdot \mathrm{f} \cdot \mathrm{gc} \mid}}{\mathrm{H}-\frac{9 \cdot \mathrm{y}}{\mid \mathrm{f}_{2 \mathrm{c} \mid}-\mathrm{k}}} \\
\mathrm{A}=\frac{\mathrm{H} \cdot \mathrm{B}-\sqrt{2}}{\mathrm{y}} \\
\lambda_{\mathrm{c}}=\left(1-\frac{\mathrm{H}}{3 \cdot \mathrm{y}}\right) \cdot \sqrt{3} \cdot \mathrm{B}+\sqrt{3}+\frac{\sqrt{2}}{\sqrt{3} \cdot \mathrm{y}} \\
\lambda_{\mathrm{t}}=\left(2 \cdot \sqrt{3}-\frac{\left|\mathrm{f}_{2 \mathrm{c}}\right| \cdot \mathrm{H}}{\sqrt{3} \cdot \mathrm{y}}\right) \cdot \mathrm{B}+\frac{\sqrt{3}}{\left|\mathrm{f}_{2 \mathrm{c}}\right|}+\frac{\sqrt{2} \cdot\left|\mathrm{f}_{2 \mathrm{c}}\right|}{\sqrt{3} \cdot \mathrm{y}} \\
\mathrm{k}_{2}=\cos \left[3 \cdot \arctan \left(\frac{2 \cdot \frac{\lambda_{\mathrm{c}}}{\lambda_{\mathrm{t}}}-1}{\sqrt{3}}\right)\right] \\
\mathrm{k}_{1}=\left[2 \cdot \cos \left(\frac{\arccos (\cos (3 \cdot \theta))}{3}\right)-1\right] \cdot \lambda_{\mathrm{t}}+\left[1-\cos \left(\frac{\arccos (\cos (3 \cdot \theta))}{3}\right)\right] \cdot 4 \cdot \lambda_{\mathrm{c}}
\end{gathered}
$$

\begin{tabular}{|c|c|c|c|c|c|c|}
\hline & $\begin{array}{l}\text { Mechanical } \\
\text { Properties }\end{array}$ & Clinker & Ceramic & $\begin{array}{l}\text { Clay Brick } \\
\text { (Germany) }\end{array}$ & $\begin{array}{c}\text { Clay Brick } \\
\text { (Afghanistan) }\end{array}$ & $\begin{array}{c}\text { Concrete } \\
\text { Masonry } \\
\text { unit }\end{array}$ \\
\hline & $f_{c}[\mathrm{MPa}]$ & -100 & $-34,8$ & $-2,4$ & $-10,2$ & $-38,7$ \\
\hline & $f_{t}[\mathrm{MPa}]$ & 5 & 1,1 & 0,293 & 1,37 & 2,17 \\
\hline & $f_{c c}[\mathrm{MPa}][1]$ & $-1,1 \times f_{c}$ & $-1,16 \times f_{c}$ & $-1,25 \times f_{c}$ & $-1,25 \times f_{c}$ & $-1,16 \times f_{c}[2]$ \\
\hline & $\sigma_{0}[\mathrm{MPa}][3]$ & $-103,5[5]$ & $-2,887 \times f_{c}$ & $-3 \times f_{c}$ & $-3 \times f_{c}$ & $-2,887 \times f_{c}[2]$ \\
\hline & $\tau_{0}[\mathrm{MPa}][3]$ & $89,6[5]$ & $2,31 \times f_{c}$ & $3 \times f_{c}$ & $3 \times f_{c}$ & $2,31 \times f_{c}[2]$ \\
\hline \multirow{3}{*}{ 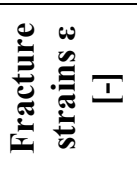 } & 1-D Compr. [4] & $4,0 \times 10^{-3}$ & $9,5 \times 10^{-3}$ & $3 \times 10^{-3}$ & $1,5 \times 10^{-3}$ & $2,3 \times 10^{-3}$ \\
\hline & 1-D Tension [6] & $1,58 \times 10^{-4}$ & $9,0 \times 10^{-4}$ & $5 \times 10^{-4}$ & $0,38 \times 10^{-4}$ & $0,178 \times 10^{-4}$ \\
\hline & 3-D Compression [3] & $8,0 \times 10^{-3}$ & $19,0 \times 10^{-3}$ & $6 \times 10^{-3}$ & $3,0 \times 10^{-3}$ & $4,6 \times 10^{-3}$ \\
\hline \multirow{2}{*}{ 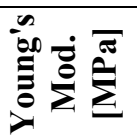 } & 1D Tension & 12750 & 1630 & 560 & 3210 & 10666 \\
\hline & 1D Compression & 24666 & 3666 & 800 & 6625 & 16800 \\
\hline
\end{tabular}

The uniaxial stresses states have been determined with own material tests, results presented in Tab. 2. For the other stress states, assumptions based on comparisons with concrete and sand were used. For the ceramic bricks, it was possible to verify these assumptions with 3D material tests that were recently executed by the Engineering Research and Development Center (ERDC) of the Army Corps of Engineers in Vicksburg, USA. There, the identical type of our bricks were examined.

Table 2. Material parameters for masonry units

[1] based on analogy observations of different types of concretes

[2] test data for concrete

[3] extrapolation of test data of concrete

[4] calculated with Young's moduli for compression and compressive strength 
[5] test data for high performance concrete

[6] calculated with Young's moduli for tension and tensile strength

\section{Tension Cut Off with Rankine Criterion}

Bricks are brittle materials and usually fail under tension. Therefore, a tensile failure surface, also known as tension cut off criterion is used, Fig. 9. The reason for that is that the Ottosen criterion might overestimate the tensile strength for some stress states. The tensile strength of the bricks is described by the Rankine criterion (principal stress criterion), Eq. 9.

$$
\mathrm{f}\left(\mathrm{I}_{1}, \mathrm{~J}_{2}, \theta\right)=2 \cdot \sqrt{3 \mathrm{~J}_{2}} \cos (\theta)+\mathrm{I}_{1}-3 \cdot f_{\mathrm{t}}=0 \text {, }
$$

where $I_{1}$ is the first invariant of the hydrostatic stress tensor, $J_{2}$ is the second invariant of the deviatoric stress tensor, $\theta$ is the Lode angle and $\mathrm{f}_{\mathrm{t}}$ is the tensile strength.

\section{Strain Rate Dependency}

Dynamic material tests on concrete specimens show a significant increase of the material compressive [4] and tensile [22] strength in dependence on strain rates. Consequently, a strain rate dependency of the material properties can also be expected for bricks. For the clinker, the ceramic and the Afghanistan clay bricks, Split-HopkinsonPressure-Bar-Tests were carried out. These tests are already described in Chapter 2. The compressive strength was studied with a normal compression set up. The tensile strength was studied with Brazilian splitting tests. For each type of brick the tests were repeated at least 5 times. With these test series, it was only possible to examine one value of the strain rate. Further tests are planned. To consider the strain rate dependency for bricks, equations published by Hartmann et al. [9] for concrete were adapted. In Fig. 10 and 11 experimental data for concrete specimens and the studied brick specimens is plotted. The red curves are the functions that were proposed by Hartmann for concrete, the blue curves are the adapted functions for bricks.

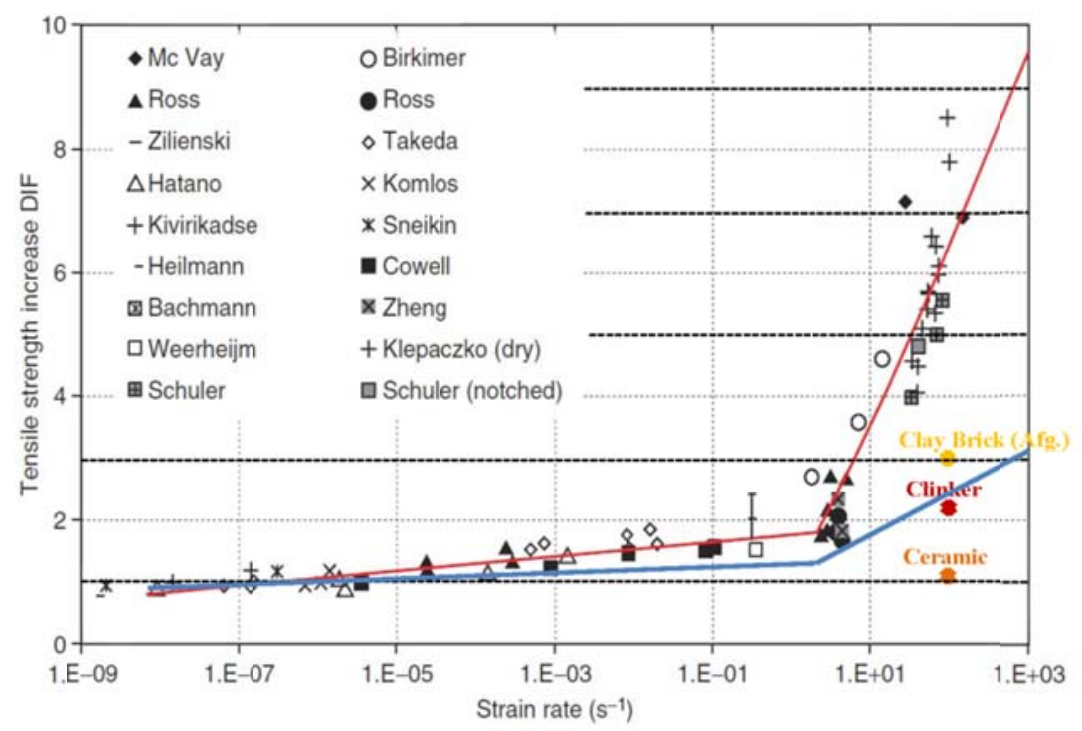

Figure 10. Dynamic increase factors for the tensile strength of concrete specimens (black symbols), Schuler et al. [21] and own tests results for bricks 


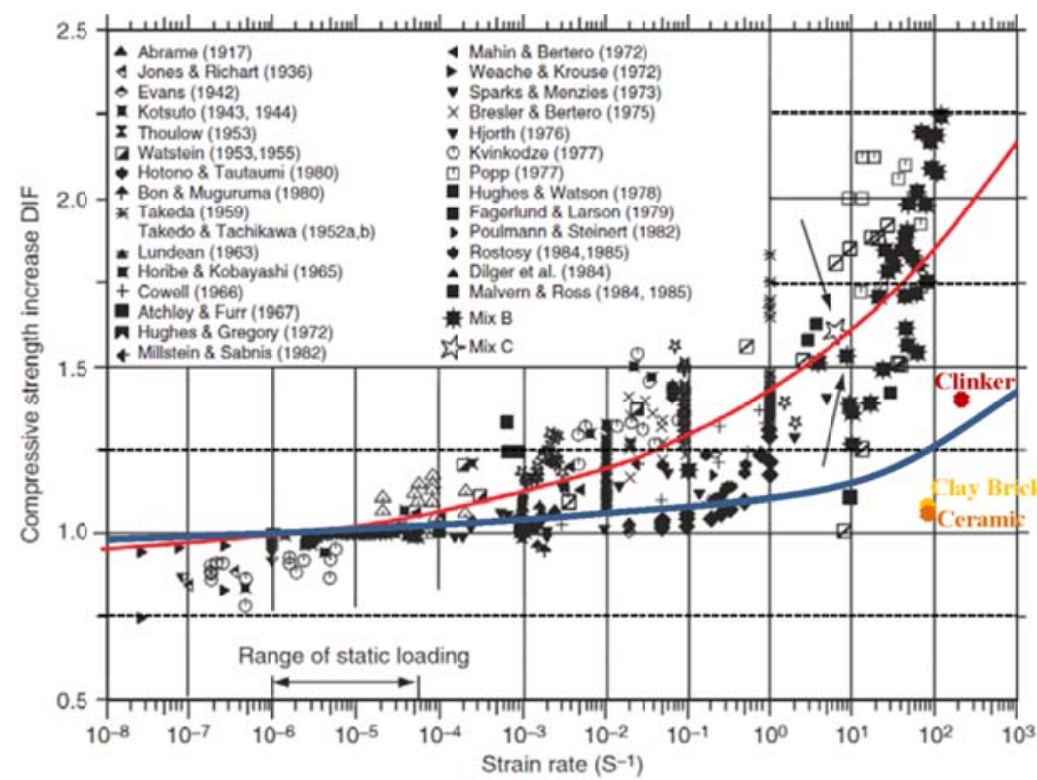

Figure 11. Dynamic increase factors for the compressive strength of concrete specimens (black symbols), Schuler et al. [21] and own tests results for bricks

The approximation for the ratio of the dynamic tensile strength to the static tensile strength reads

$$
\frac{f_{\mathrm{t}, \text { dyn }}}{\mathrm{f}_{\mathrm{t}, \text { stat }}}=\left\{\begin{array}{ccc}
0.42 \cdot\left(0.13 \cdot \log \left(\frac{\dot{\varepsilon}}{\dot{\varepsilon}_{0}}\right)+1.78-1.0\right)+1.0 & \text { for } & \dot{\varepsilon} \leq 2 \mathrm{~s}^{-1} \\
0.42 \cdot\left(1.45 \cdot \ln \left(1+\frac{\dot{\varepsilon}}{\dot{\varepsilon}_{0}}\right)+0.23-1.0\right)+1.0 & \text { for } & \dot{\varepsilon}>2 \mathrm{~s}^{-1}
\end{array}\right.
$$

and for the dynamic compression strength to the static compression strength reads

$$
\frac{\mathrm{f}_{\mathrm{c}, \text { dyn }}}{\mathrm{f}_{\mathrm{c}, \text { stat }}}=0.7 \times\left(0.5\left(\left(\frac{\dot{\varepsilon}}{\dot{\varepsilon}_{0}}\right)^{0.13}+0.9-1.0\right)+1.0 \quad \text { with } \quad \dot{\varepsilon}_{0}=\frac{1}{\mathrm{~s}^{-1}}\right.
$$

These functions do not distinguish between the three types of bricks. If a distinction is wished, the functions can be adjusted by changing the values 0.42 (Eq. 13) respectively 0.7 (Eq. 14).

\section{Equation of State}

For Hydrocode simulations, see Chapter 4, the hydrostatic material behavior is taken into account. There are several models existing to describe the effect of hydrostatic pressures. For porous materials usually the so called porous equation of state (EoS) is used. This EoS describes, as a function of pressure, whether the material behaves elastically, whether the pores in the material are collapsing, or whether the pores are already compacted. To calibrate such a porous EoS, at least some material tests have to be carried out to determine the pressure and the volume at the beginning of the collapse of the pores, and that pressures and density at which the porous material is completely compacted. No suitable test data could be found in the literature and it was not possible to determine such data with experimental tests up to now. Some scientists, e.g. Riedel [16] and Gebbeken and Hartmann [6], determined or estimated these parameters for concrete by analyzing the properties of the components of concrete. One could suggest doing the same for bricks. During this project, this possibility was examined. But the problem is that this strategy can only give rough estimations, because the components and the minerals of the masonry units are not known. The principal aim of the development of this material model is to analyze the behavior of masonry walls under blast 
loads. And under such dynamic loadings a linear EoS, which is based on the bulk modulus, is sufficient. A reason for this simplification is that the hydrostatic pressure in the brick is limited under blast loads because of the tensile failure of the bricks (failure due to lateral deformation of the joints). For simulations of contact detonations a more sophisticated EoS is needed, because higher pressures will occur.

\section{Elastic, Plastic and Damaged Material Status, Residual Strength}

The material stress-strain-behavior can generally be characterized by three domains: elastic, plastic and damaged. This characterization is not so clear if the transition between the domains is not clearly identifiable. Under tensile loadings, bricks do not show a plastic domain. They seem to behave elastically until brittle fracture. Under compression, some plastification can be observed by the clay bricks. The other bricks show a completely brittle failure under every stress state. In order to develop a suitable numerical model, it is assumed that the brick behaves elastically under every stress state until a maximum stress is reached. Then a plastification of the material is assumed, that is limited by $\varepsilon_{\text {eff,B }}$. This parameter describes the effective strain when fracture and degradation of the material properties begins. When $\varepsilon_{\text {eff,B }}$ is exceeded, the material gets damaged and begins to damage until failure. Fig. 12 explains the concept.

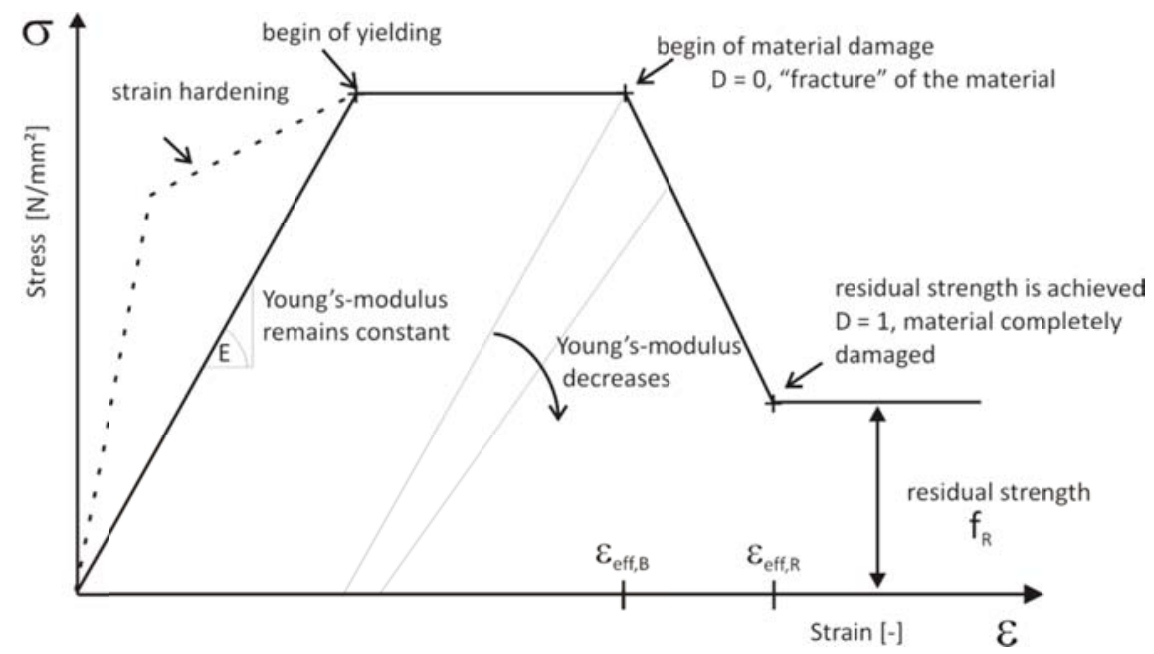

Figure 12. Schematic representation of the material status, the fracture strains, residual strength and strain when residual strength is achieved.

\section{Fracture Strains and Residual Strength on the Compressive Meridian}

This model is based on assumptions and comparisons with Bierwirth's test data for mortar. In the near future triaxial test data for bricks will be used and the assumptions can be controlled. Fig. 13 shows the effective fracture strain $\varepsilon_{\text {eff,B }}$ as a function of the triaxiality $\eta$. In this figure, a small figure is included, which represents test data from Bierwirth [3] for mortar. He conducted the tests using a pressure cell applying different confining pressures. These tests show that the fracture strains are increasing with the decrease of the triaxiality. To describe the fracture strains for every stress state the following values are needed:
$\varepsilon_{\text {eff,B,1D }}$
Fracture strain, 1-axial compression test
$\varepsilon_{\text {eff,B,3D }}$
Fracture strain, 3-axial compression test
$\varepsilon_{\text {eff,B,1Z }}$
Fracture strain, 1-axial tensile test 
$\eta_{\mathrm{B}, 1 \mathrm{D}}$

Triaxiality by fracture, 1 -axial compression test $(-0.333)$

$\eta_{\mathrm{B}, 3 \mathrm{D}}$

Triaxiality by fracture, 3 -axial compression test $(-0.51)$

$\eta_{\mathrm{B}, 1 \mathrm{Z}}$

Triaxiality by fracture, 1 -axial tensile test $(0.333)$

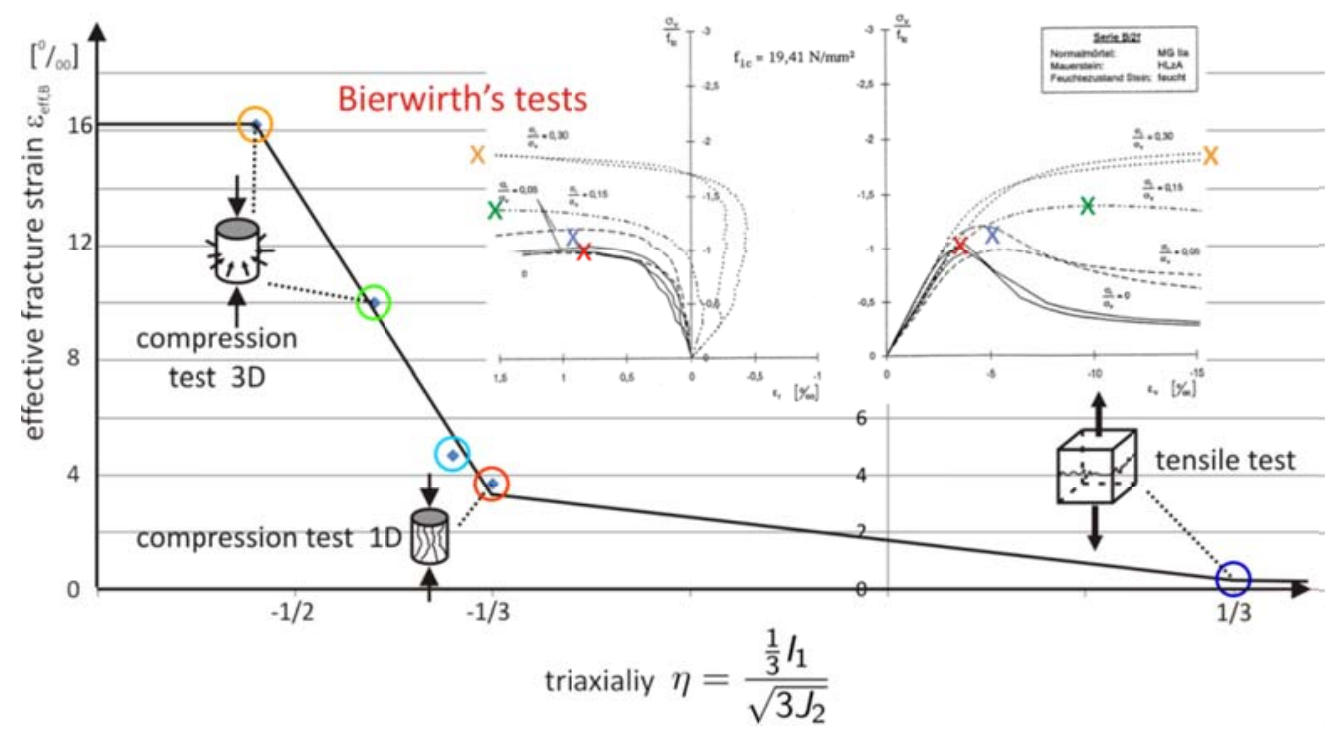

Figure 13. Effective fracture strain as a function of the triaxiality $\eta$

The interpolation between the measured data points of the effective fracture strains is described by linear functions (Eq. 15). These four functions are plotted in Fig. 13.

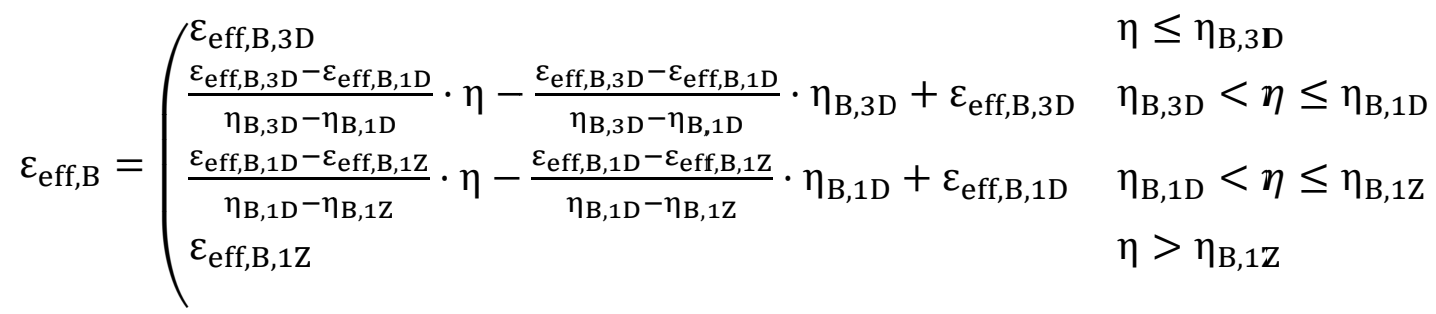

In the two small diagrams in Fig. 13, which show Bierwirth's material tests, the influence of the stress state on the residual strength can be observed. Tab. 3 shows the results for the residual strength for Bierwirth's material tests. These values correspond to the colored crosses and circles in Fig. 13.

Table 3. Residual strength for different stress states, based on Bierwirth's material tests

\begin{tabular}{lcccc} 
& \multirow{2}{*}{$\begin{array}{c}\text { Compression } \\
\text { 1-axial }\end{array}$} & \multicolumn{3}{c}{ Confining pressure / Principal stress } \\
\cline { 3 - 5 } & & 0,05 & 0,15 & 0,3 \\
\hline Triaxiality $(\boldsymbol{\eta})$ & $-0,333$ & $-0,386$ & $-0,51$ & $-0,762$ \\
Residual strength $\left(\mathbf{f}_{\mathbf{R}}\right)$ & 0,35 & 0,67 & 1 & 1 \\
\hline
\end{tabular}

This data leads to the following formulae for the residual strength:

$$
\mathrm{R}=\left\{\begin{array}{cc}
1 & \eta \leq-0,510 \\
4 \cdot \eta^{2}+0,078 \cdot \eta & -0,510 \leq \eta \leq 0 \\
0 & \eta>0
\end{array}\right.
$$


Equation 16 is illustrated in Fig. 14. The definition of the residual strength after fracture is one of the complicated tasks that were encountered during the project. Luckily, Bierwirth's test gave an idea how the post fracture behavior must look like and at which strain the residual strength is achieved. For all stress states, this strain is at about 3 times higher than the strain when the material begins to fracture $\left(\varepsilon_{\mathrm{eff}, \mathrm{R}} \approx 3 \cdot \varepsilon_{\mathrm{eff}, \mathrm{B}}\right)$.

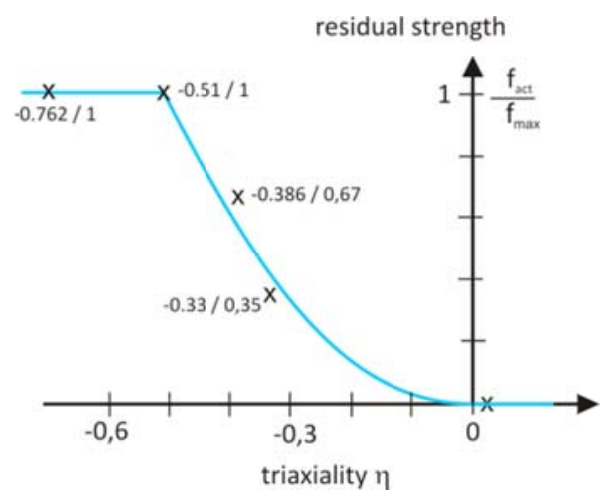

Figure 14. Residual strength as a function of the triaxiality of the stress state

Concluding remark: If the material behavior after fracture should be described, the fracture strains, the residual strength and the strain at which the residual strength is achieved are important material properties that are needed. Fig. 15 shows schematically the material post fracture behavior for several stress states. These material properties must be determined with experiments for one, two and three dimensional stress states.

\section{Damage Model}

The damage model is needed to describe the decay of the material strength and the material stiffness after fracture. It is assumed that the material damage $D$ begins as $\varepsilon_{\text {eff,B }}$ is exceeded. The developed damage model is based on the effective strain of the material. There are two input parameters for the model: $\varepsilon_{\mathrm{eff}, \mathrm{B}}$ and $\varepsilon_{\mathrm{eff}, \mathrm{R}}$. The latter is the effective strain when the residual strength is achieved. These two effective strains are quite different for different stress states and must be distinguished for compressive and tensile states. Up to now, the values $\varepsilon_{\text {eff,B }}$ and $\varepsilon_{\text {eff,R }}$ are estimated for the bricks for 3-dimensional stress states. Because these values are known for mortar, the estimation should not be too bad. But it is planned to validate them with material tests.

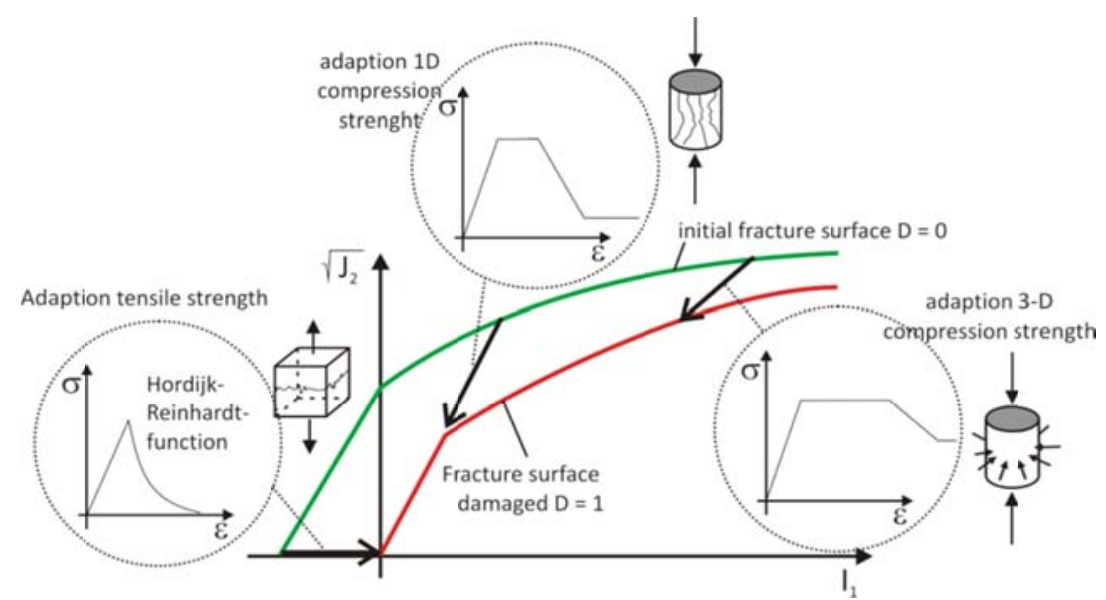

Figure 15. Adaption of the fracture surface due to material damage for several stress states 


\section{Adaption of the Material Stiffness}

After fracture, a decay of the material stiffness is observed. Stress-strain-diagrams of compression tests of Oliveira [14] show, that the stiffness decreases significantly. These diagrams show that if the residual strength in the $1 \mathrm{D}$ compression state is only $15 \%$ of the original undamaged strength, the stiffness is about one third of the original stiffness. So the shear modulus can be approximated by

$$
G_{\text {brick }}=G_{0} \cdot(1-D)+\frac{1}{3} \cdot G_{0} \cdot D \text {, }
$$

where $G_{0}$ is the undamaged stiffness and $D$ the material damage.

\section{Adaption of Young's Moduli, Tensile and Compression Regime}

Bricks show a significant difference between the tensile and the compressive Young's Modulus, Tab. 2. This is considered by distinguishing with the help of the triaxiality

$$
E=\left\{\begin{array}{cl}
E_{\text {tensile }} & \text { for } \eta>0 \\
E_{\text {compression }} & \text { for } \eta<0
\end{array}\right.
$$

The difference of the stiffness can be explained by micro cracks in the brick material that reduce the tensile stiffness.

\section{NUMERICAL SIMULATIONS}

The material model presented in Chapter 3 was implemented with a user subroutine in ANSYS AUTODYN. In order to validate the material model, some experimental investigations, which are described in Chapter 2, were numerically simulated. The numerical results were compared to results of the tests. In the following, the numerical simulations of uniaxial tensile and uniaxial compression tests that have been carried out on masonry bricks will be presented.

\subsection{Hydrocode simulations}

As mentioned above, the numerical simulations have been carried out applying the software ANSYS AUTODYN. This software is a Hydrocode developed to numerically model engineering problems. A Hydrocode is capable to solve large deformation and large strain transient problems that occur on a short time scale. This code is based on the finite difference method (FDM). The FDM solves partial differential equations by the transformation of differential terms into difference quotients. The FDM in ANSYS AUTODYN is based on the integral difference technique developed by Noh [13]. Noh derived the integral difference method by combining Green's Theorem with the mean value theorem. Green's Theorem gives the relation between the boundary integral and area integral. According to Benson [2], in almost all Hydrocodes, the conservation equations are integrated in time. The deviatoric and hydrodynamic terms in the material tensor are usually modeled separately. In this way, the solution is advanced in time using an explicit integration scheme, because stress waves 
and shocks are an important part of the solution for hydrodynamic calculations, and they must be resolved accurately in both space and time. In an explicit time integration, the solution is advanced from time $\mathrm{t}^{\mathrm{n}}$ to time $\mathrm{t}^{\mathrm{n}+1}$ without any iterations. The difference between $\mathrm{t}^{\mathrm{n}}$ and $\mathrm{t}^{\mathrm{n}+1}$ is the time step $\Delta \mathrm{t}$. The solution at the beginning of the time step is overwritten by the solution at the end of the step. The explicit time integration is more accurate and efficient for simulations involving shock wave propagation, large deformations and large strains, nonlinear material behavior, complex contact and fragmentation. But the explicit methods are only stable if the time step is smaller than the so-called critical time step $\Delta \mathrm{t}_{\mathrm{cr}}$, i.e., the time increment between successive time points. This is based on the highest natural frequency in the system. The stability of the time step $\Delta \mathrm{t}$ is limited to the Courant-Friedrich-Levi (CFL) criterion, Eq. 28.

$$
\Delta t \leq f \times \frac{\Delta x}{c}
$$

where $\Delta \mathrm{t}$ is the time step, $\mathrm{f}$ is the stability time step factor, $\Delta \mathrm{x}$ is the element size and $\mathrm{c}$ is the wave propagation speed. Fig. 16 presents the computational cycle of ANSYS AUTODYN, which is used to compute the numerical states of the problem.

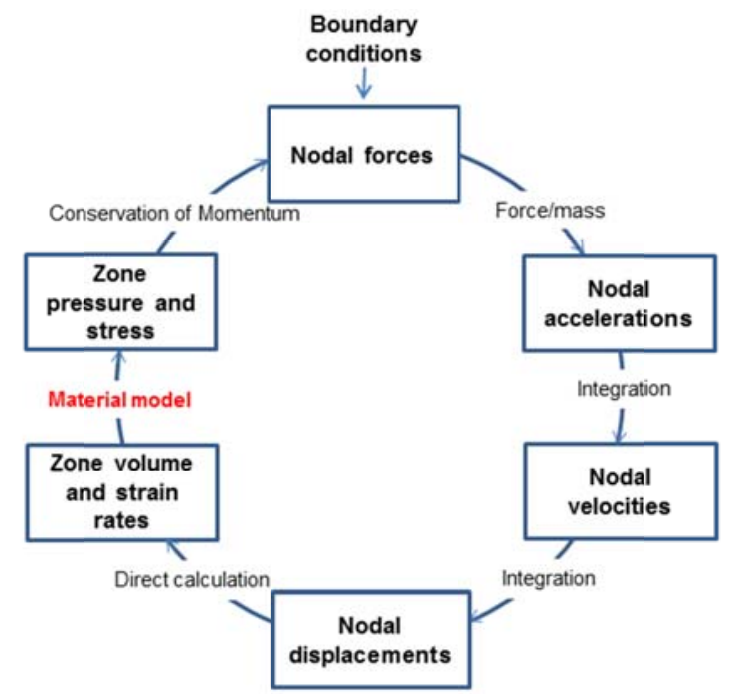

Figure 16. Computational cycle in ANSYS AUTODYN, based on [1]

According to AUTODYN's manual [1], the computational cycle is as follows. At first, the boundary conditions are updated and combined with the nodal forces which were computed during the previous time cycle. Next, the nodal accelerations of the element nodes are obtained by calculating the ratio of the nodal force and the mass. The nodal accelerations are integrated yielding the nodal velocities. In the following step, the nodal velocities are integrated providing the nodal displacements. The element zone volume is obtained from the nodal displacements and the strain rates are obtained from the nodal displacement. With the help of the material model, which is provided by ANSYS AUTODYN or implemented by the user, pressures and the stress states are calculated. Also in this step, with the help of the energy equation (conservation of momentum), the energies may be obtained, providing nodal forces that can be used for the next integration cycle.

This computational cycle works on a single finite element as given in Fig. 17. 


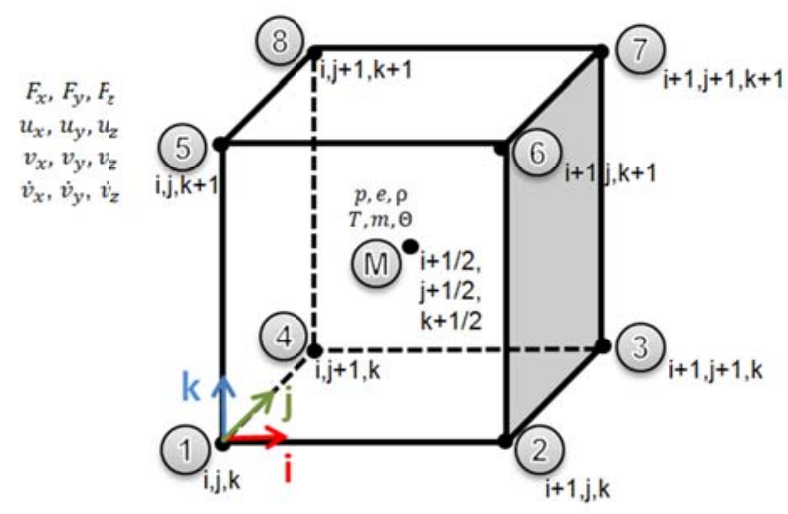

Figure 17- Hexaeder element, variables in the element node (1 to 8) and ellement midpoint $\mathrm{M}$

The forces $\mathrm{F}$, the displacement $\mathrm{u}$, the velocities $\mathrm{v}$ and the accelerations $\dot{v}$ are computed in the element nodes 1 to 8 . The hydrostatic pressure $\mathrm{p}$, the internal energy e, the density $\rho$, the tensor stresses $T$, the mass $\mathrm{m}$ and the temperature $\Theta$, are computed in the element midpoint $\mathrm{M}$. The variables that are computed in the midpoint $\mathrm{M}$ are constantly distributed across the finite element. The variables $\mathrm{F}, \mathrm{u}, \mathrm{v}$ and $\dot{v}$ are linearly distributed across the element.

\subsection{Validation of the brick material model}

At first the validation of the implementation of the material model in ANSYS AUTODYN was carried out. At the beginning numerical simulations were carried out using just one single element as presented above, Fig. 17. For the sake of the implementation validation, a brick model with a volume of $1 \mathrm{~m} \times 1 \mathrm{~m} \times 1 \mathrm{~m}$ was defined, Fig. 18 (a). This volume is numerically represented using the 8 node hexahedral element as implemented in ANSYS AUTODYN, Fig. 17. The four lower nodes (1 to 4 ) of the element were fixed in $z$ direction. In $\mathrm{x}$ and $\mathrm{y}$ direction they are free. To the upper nodes (5 to 8), a deformation was applied in $\mathrm{z}$ direction, Fig. 18 (b). These boundaries are in accordance to the deformation driven tensile and compression tests. Alterating the sign of the displacement in z-direction, a tensile ( $\mathrm{z}$ positive) or a compression ( $\mathrm{z}$ negative) test can be simulated.

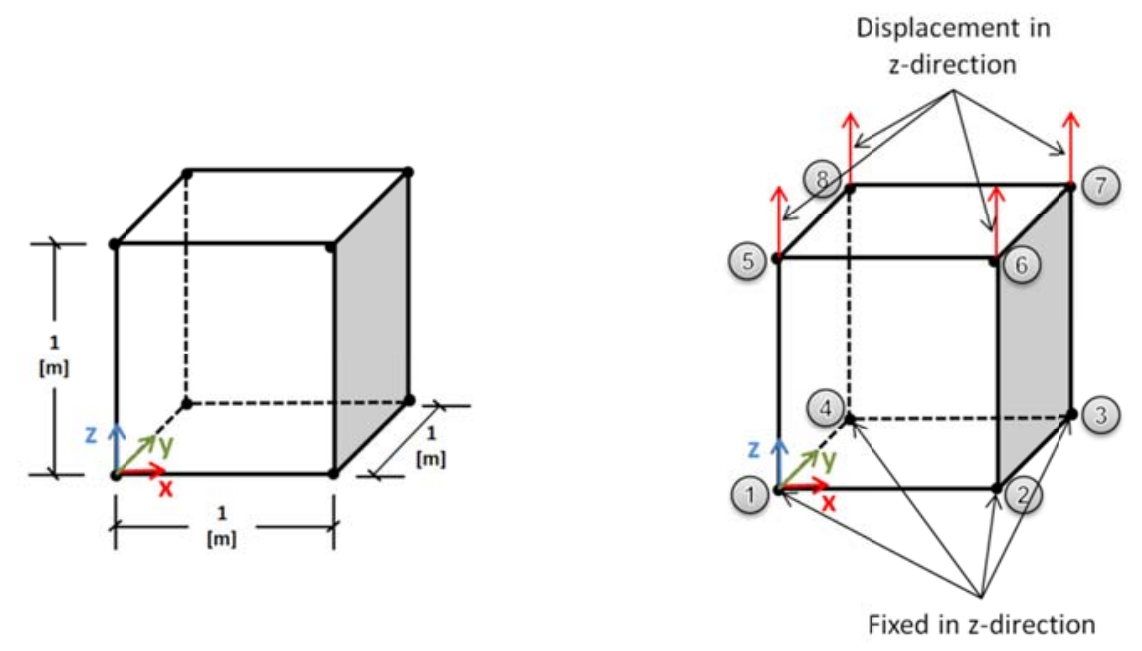

Figure 18. Schematic representation (a) of the dimensions of the element used in the simulation and (b) of an 8-node element used for the verification of the material model 
With the single-cell simulation, it is possible to check whether the implementation is correct or not. In this way, firstly, the mechanical properties presented in Tab. 2 obtained from the tests were assigned in ANSYS AUTODYN. Secondly, the stresses and strains obtained from the numerical simulations were compared with the continuum mechanics theory. In the following the validation of the tensile and compressive simulation will be presented in detail for the ceramic brick.

The element used in the simulation is subjected to a deformation in z-direction producing a normal stress in this direction, simulating a uniaxial tensile or compression test. Due to this uniaxial stress, the normal stresses in $\mathrm{x}$ and $\mathrm{y}$ direction, and also the shear stresses and shear strains, are null. The extension (tensile test) or contraction (compressive test) of the element is accompanied by lateral extension or contraction, resulting in normal strains. The results of the tests show a linear behavior until the fracture, in this way, the strains in which the body is subjected can be obtained due to the constitutive law of the material. The constitutive law is described by the following equations from the continuum mechanics

$$
\begin{aligned}
& \varepsilon_{\mathrm{xx}}=\frac{1}{\mathrm{E}}\left[\sigma_{\mathrm{xx}}-v\left(\sigma_{\mathrm{yy}}+\sigma_{\mathrm{zz}}\right)\right] \\
& \varepsilon_{y y}=\frac{1}{\mathrm{E}}\left[\sigma_{\mathrm{yy}}-v\left(\sigma_{\mathrm{zz}}+\sigma_{\mathrm{xx}}\right)\right] \\
& \varepsilon_{\mathrm{zz}}=\frac{1}{\mathrm{E}}\left[\sigma_{\mathrm{zz}}-v\left(\sigma_{\mathrm{xx}}+\sigma_{\mathrm{yy}}\right)\right]
\end{aligned}
$$

were used, where $\varepsilon$ are the normal strains, E the Young's Modulus, $\sigma$ the normal stresses and $v$ is the Poisson's ratio.

In order to validate the implementation, the last state of the linear region at $t=95 \mathrm{~ms}$ was analyzed. For the tensile test, a constant velocity of $0,005 \mathrm{~m} / \mathrm{s}$ was given. The Poisson's ratio in this case was approximated to 0,2 and the Young's Modulus, E $=1630 \mathrm{MPa}$, was obtained from the tensile test. The displacement obtained in this state is $\Delta \mathrm{l}=\mathrm{v} \times \mathrm{t}=$ $0,005 \times 95 \times 10^{-3}=0,475 \mathrm{~mm}$. This test simulates a uniaxial tensile test. In this theoretical case, the normal stress in $\mathrm{x}$ and $\mathrm{y}$ direction, the shear stresses and shear strains are zero. Thus, the deformation analytically obtained in $\mathrm{z}$ direction is $\varepsilon_{\mathrm{zz}}=0,475 / 1000=4,75 \times 10^{-4}$. The stress in $\mathrm{z}$-direction can be obtained using Eq. 22. The strains in $\mathrm{x}$ and $\mathrm{y}$ direction are determined from Eq. 20 and 21. The results from the numerical simulation and the continuum theory are in good agreement, Tab. 4. The results of the simulations are presented in Fig. 19.

With the same method the implementation was validated for the compressive tests. These results are plotted in Tab. 4 and Fig. 20. 
Table 4. Stresses and strains of the numerical simulations and theoretical values

\begin{tabular}{ccccc} 
& \multicolumn{2}{c}{$\mathbf{t}=\mathbf{9 5} \mathbf{~ m s}, \mathbf{v}=\mathbf{0 , 0 0 5 m} / \mathbf{s}$} & \multicolumn{2}{c}{$\mathbf{t}=\mathbf{9 , 3 5} \mathbf{~ m s}, \mathbf{v}=\mathbf{1 , 0} \mathbf{m} / \mathbf{s}$} \\
\cline { 2 - 5 } & \multicolumn{2}{c}{ Uniaxial Tensile, $\mathbf{E}=\mathbf{1 6 3 0 M P a}$} & Uniaxial Compression, E=3666MPa \\
\cline { 2 - 5 } & Simulation & Theory & Simulation & Theory \\
\hline $\boldsymbol{\sigma}_{\mathrm{zz}}$ & $0,760 \mathrm{MPa}$ & $0,774 \mathrm{MPa}$ & $34,8 \mathrm{MPa}$ & $34,28 \mathrm{MPa}$ \\
$\boldsymbol{\sigma}_{\mathbf{x x}}, \boldsymbol{\sigma}_{\mathbf{y y}}$ & 0 & 0 & 0 & 0 \\
$\boldsymbol{\sigma}_{\mathbf{x y}}, \boldsymbol{\sigma}_{\mathbf{y z}}, \boldsymbol{\sigma}_{\mathrm{zx}}$ & 0 & 0 & 0 & 0 \\
$\boldsymbol{\varepsilon}_{\mathbf{z z}}$ & $4,74 \times 10^{-4}$ & $4,75 \times 10^{-4}$ & $-9,5 \times 10^{-3}$ & $-9,35 \times 10^{-3}$ \\
$\boldsymbol{\varepsilon}_{\mathbf{x x}}, \boldsymbol{\varepsilon}_{\mathbf{y y}}$ & $-8,49 \times 10^{-5}$ & $-9,5 \times 10^{-5}$ & $1,89 \times 10^{-3}$ & $1,87 \mathrm{x} 10^{-3}$ \\
$\boldsymbol{\varepsilon}_{\mathbf{x y}}, \boldsymbol{\varepsilon}_{\mathbf{y z}}, \boldsymbol{\varepsilon}_{\mathbf{z x}}$ & 0 & 0 & 0 & 0 \\
\hline
\end{tabular}
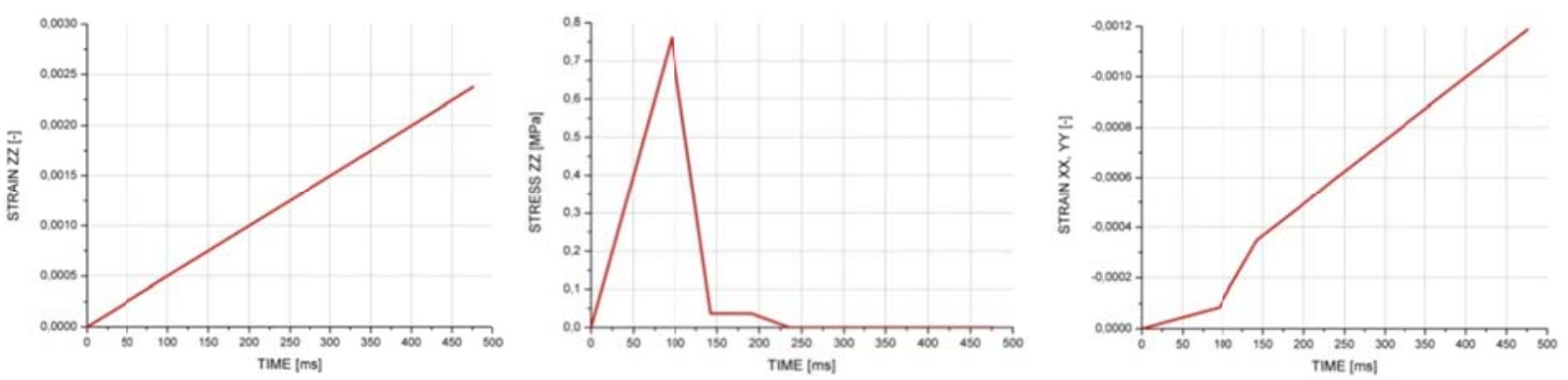

Figure 19. Normal stress and strains obtained from the numerical simulations for the ceramic brick under tension
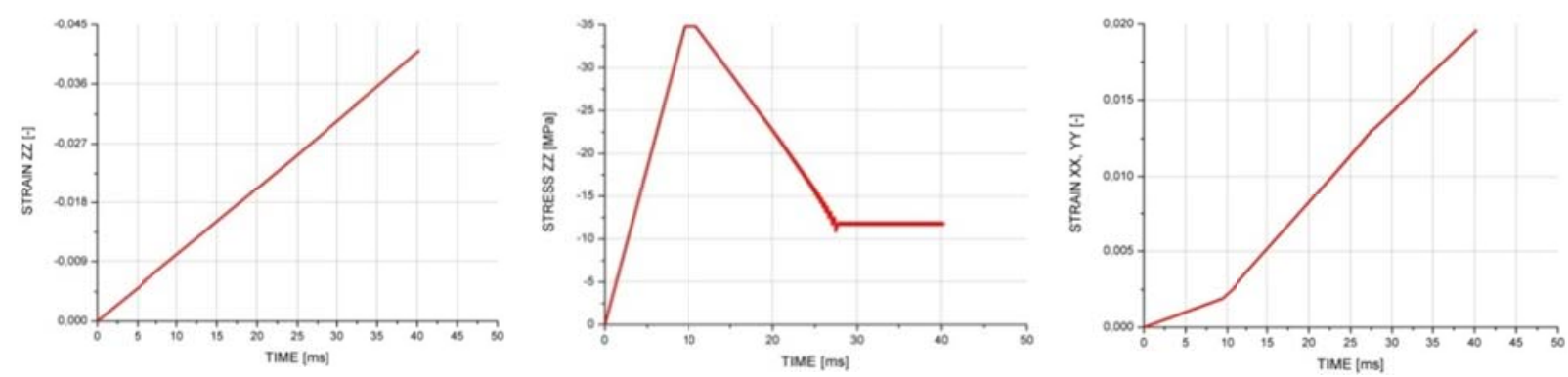

Figure 20. Normal stress and strains obtained from the numerical simulations for the ceramic brick under compression

Finally, the numerical results were compared with the static tensile and compression tests results. The stress components in z-direction of the numerical simulation using the single cell and the results of the tensile and compression tests are plotted in Fig. 21.
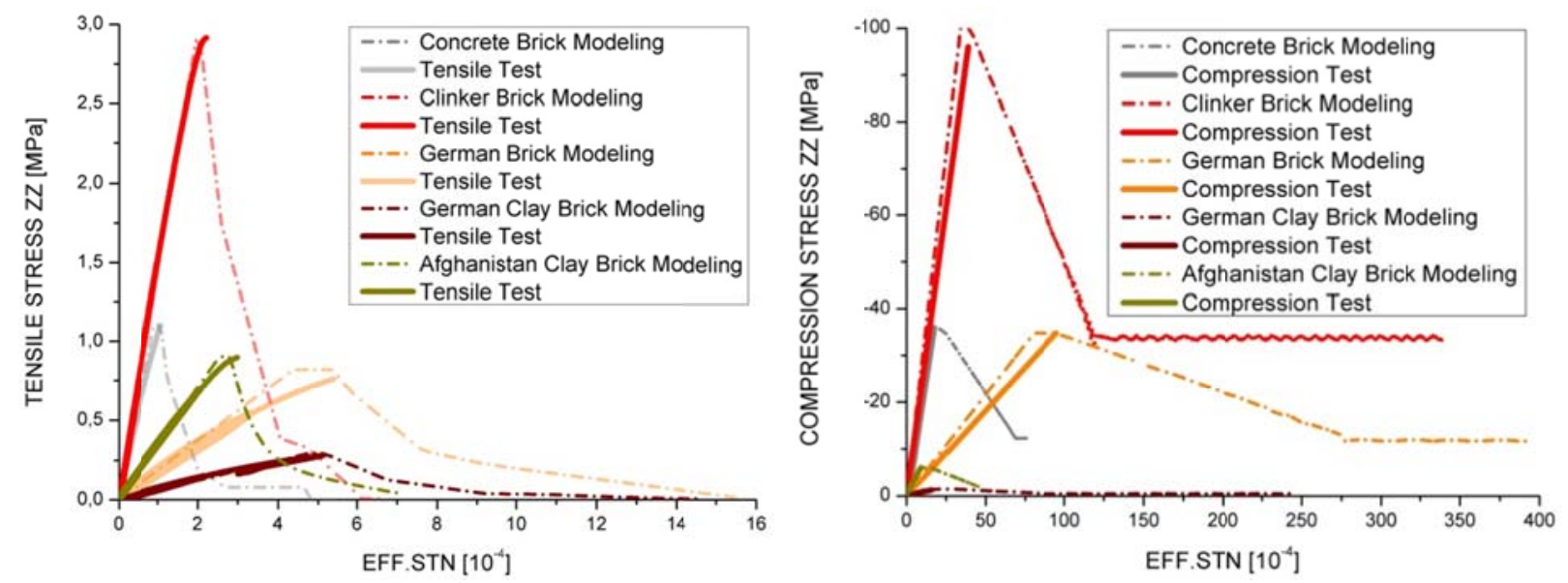

Figure 21. Validation of (a) tensile and (b) compression static experimental investigations 
Fig. 21 shows comparisons between the results of the simulations and the results of static tensile and compression experiments conducted for each of the five bricks presented in Fig. 1. In these graphics, the stress-strain diagrams obtained in the tests and the stressstrain in z-direction obtained from the simulations are presented. As can be seen, the results from the tests and the numerical simulations are in good agreement. For these simulations, the strain rate dependency was inactivated in the material models.

\section{CONCLUSION}

A detailed micro-model has been developed in order to simulate masonry walls. Two material models, one for bricks and one for mortar have been developed. In this paper, the material model developed for masonry bricks was presented. The challenge was to describe the material under 3-dimensional stress states including strain rate dependency, material failure and degradation of material properties. For this purpose, available literature has been studied and in addition own static and dynamic material tests have been carried out.

The new material model is somewhat a combination of material models for static 2D simulations, as they were suggested e.g. by Lourenco [12], and dynamic material models published by Johnson and Holmquist [10], Riedel [17] or Gebbeken and Hartmann [5]. The new material model is able to describe three dimensional stress states considering the post fracture behavior of the materials. The material model can be easily adapted to other bricks.

Furthermore, the material model can be used for different loads, being static or dynamic. The material model was validated under tensile and compressive static loads for the bricks and a validation of a single cell element was presented in this paper. The authors are about to perform more physical tests and numerical simulations of masonry specimens and entire walls.

\section{Acknowledgements}

The support of LTC Andreas Heckersbruch of the Armed Forces Office and Mr. Albert Burbach of the WTD52 is gratefully acknowledged. Many thanks go to Dr. Andrea Kustermann and her team at the University of the Bundeswehr for executing the static material tests. Special thanks to Dr. George Solomos and Dr. Marco Peroni (JRC Ispra) for the dynamic material test data.

\section{REFERENCES}

[1] ANSYS AUTODYN User's Manual. ANSYS, Inc. Mechanical APDL Product Launcher Release 13.0, 2010.

[2] Benson, D. J. "Computational methods in Lagrangian and Eulerian hydrocodes". Computer Methods in Applied Mechanics and Engineering, 99: p. 235-394, 1992.

[3] Bierwirth, H. "Dreiachsiale Druckversuche an Mörtelproben aus Lagerfugen von Mauerwerk”. Dissertation, Technische Universität München, Deutschland 1995. 
[4] Bischoff, P. H., Perry, S. H. "Impact Behavior of Plain Concrete Loaded in Uniaxial Compression”. Journal of Engineering Mechanics, June (6): p. 685-693, 1995.

[5] Brameshuber, W., Graubohm, M., Schmidt, U. "Festigkeitseigenschaften von Mauerwerk", Mauerwerkskalender 2006 - Teil 4: Scherfestigkeit, Kapitel A IV, p. 193226. Ernst \& Sohn Verlag, 2006.

[6] Gebbeken, N., Hartmann, T. "A new Methodology for the Assessment of the EoS Data of Concrete. International Journal of Protective Structures, Vol 1, No 3, Multi-Science Publishing Co Ltd. UK, ISSN 2041-4196, 2010, p. 299-317

[7] Gebbeken, N., Linse, T., Araújo, T. "Modeling Masonry under dynamic loadings, material models, numerical simulations". $9^{\text {th }}$ International Conference on Shock \& Impact Loads on Structures. Fukuoka, Japan. Nov. 16 - 18, 2011.

[8] Hao, H., Tarasov, B. G. "Experimental study of dynamic material properties of clay brick and mortar at different strain rates". Australian Journal of Structural Engineering, 8: 117$131,2008$.

[9] Hartmann, T., Pietzsch, A., Gebbeken, N. “A Hydrocode Material Model for Concrete”. International Journal of Protective Structures, Multi-Science Publishing Co Ltd. UK, ISSN 2041-4196, Volume 1, Number 4, Dec 2010, p. 443-468

[10] Johnson, G. R., Holmquist, T. J. "An improved computational constitutive model for brittle materials". High-pressure science and technology 1993, 309: p. 981-984, 1994.

[11] Linse, Tobias: "Materialmodelle für Mörtel und Ziegel für die diskrete Modellierung von Mauerwerk unter dynamischen Einwirkungen". Dissertation, Universität der Bundeswehr München, publication planned in 2012.

[12] Lourenço, P. J. B. B. “Computational Strategies for Masonry Structures”. Dissertation, Technische Universiteit Delft, 1996.

[13] Noh, W. F., Woodward, P. "SLIC (Simple Line Interface Calculation)", Lecture Notes in Physics 59, Spring-Verlag, Berlin (1976).

[14] Oliveira, D. V. de C. "Experimental and numerical analysis of blocky masonry structures under cyclic loading”. Dissertation, Universidade do Minho, Portugal, 2003.

[15] Pluijm, R. van der: "Material Properties of Masonry and its Comportments under Tension and Shear". In: 6th Canadian Masonry Symposium, University of Saskatchewan, 1992.

[16] Riedel, W. "Beton unter dynamischen Lasten - Meso- und makromechanische Modelle und ihre Parameter". Dissertation, Fakultät für Bauingenieur- und Vermessungswesen, Universität der Bundeswehr München, Deutschland 2000. 
[17] Sarangapani, G., Reddy, B. V. V., Jagadish, K. S. "Brick-Mortar Bond and Masonry Compressive Strength". Journal of materials in civil engineering, 17(2): p 229-237, 2005.

[18] Schickert, G. "Formfaktoren der Betondruckfestigkeit". Die Bautechnik, Band 2, S. 5257, Verlag Ernst \& Sohn, 1981

[19] Schubert, P. "Eigenschaftswerte von Mauerwerk, Mauersteinen und Mauermörtel". Mauerwerk Kalender 2005, 30: p. 127-130, Verlag Ernst \& Sohn, 2005.

[20] Schubert, P. "Eigenschaftswerte von Mauerwerk, Mauersteinen und Mauermörtel”. Mauerwerk Kalender 2007, p. 3-24. Verlag Ernst \& Sohn, 2007.

[21] Schuler, H., Mayrhofer, C., Thoma, K. "Spall experiments for the measurement of the tensile strength and fracture energy of concrete at high strain rates". International Journal of Impact Engineering, 32(10): p. 1635-1650, 2006.

[22] Speck, K. "Beton unter mehraxialer Beanspruchung - Ein Materialgesetz für Hochleistungsbetone unter Kurzzeitbelastung”. Dissertation, Fakultät für Bauingenieurwesen, Technische Universität Dresden, Deutschland, Oktober 2007.

[23] Thomée, B. "Physikalisch nichtlineare Berechnung von Stahlfaserbetonkonstruktionen". Dissertation, Technische Universität München, Deutschland, 2005.

[24] Vermeltfoort, A. Th., Pluijm, R. van der. "Strength and deformation properties of masonry to be used in computer calculations". In: Proc. of the 9th IBMac (International Brick and Masonry Conference), p. 244-251, 1991.

[25] Willam, K. J., Warnke, E. P. "Constitutive Model for the Triaxial Behavior of Concrete". In: IVBH, IABSE AIPC (Eds): Concrete Structures subjected to triaxial stresses, 17th - 19th May, 1974, ISMES - Bergamo Italy, 1974. 